\title{
Análisis de sentencias emitidas por tribunales salvadoreños relacionadas con delitos de pornografía de personas menores de 18 años
}

\author{
Hazel Jasmín Bolaños-Vásquez' \\ Miguel Ángel Boldova-Pasamar² \\ Carlos Fuertes-Iglesias ${ }^{3}$ \\ Recibido: 21/02/2014 - Aceptado: 05/05/2014
}

\begin{abstract}
Resumen
En el presente artículo se realiza un análisis de tres sentencias emitidas por tribunales salvadoreños relacionadas con delitos de utilización de personas menores de 18 años e incapaces o deficientes mentales en pornografía y de posesión de pornografía, regulado en los artículos 173 y 173-A del Código Penal salvadoreño, y en cuya ejecución los sujetos activos han utilizado tecnologías de la información y la comunicación (TIC) como medio comisivo.

El objetivo de este análisis es examinar la aplicación de la legislación penal que realiza el juzgador salvadoreño en sus sentencias, y de esta manera poder encontrar aquellos aspectos que necesitan ser mejorados para garantizar la persecución de estos delitos que afectan gravemente la indemnidad sexual de la niñez y adolescencia.
\end{abstract}

\section{Palabras clave}

Pornografía infantil, la tecnología de la información y las comunicaciones, los medios de comisión, delitos contra la libertad e indemnidad sexuales

\section{Abstract}

This article analyzes three sentences issued by Salvadorean courts related to the use of minors and mentally disabled minors in child pornography as well as pornography possession, as regulated in Articles 173 and 173 -A of the Salvadoran Penal Code, and for which performance the perpetrators have used information and communication technologies (ICT) as the means of commission.

The aim of this analysis is to examine the application of criminal law as executed by Salvadoran judges when dictating sentences and thus find those aspects which need to be improved in order to ensure the prosecution of such offenses that so seriously affect the sexual indemnity of children and adolescents.

\section{Keywords}

child pornography, information and communication technologies, means of commission, offenses against sexual indemnity and freedom.

Hazel Jasmín Bolaños Vásquez. Investigadora académica de la Universidad Tecnológica de El Salvador, Doctora en Derecho con especialidad en Derechos Humanos y Derecho Penal por la Universidad de Zaragoza. Correo electrónico: hazel.bolanos@utec.edu.sv

2 Miguel Ángel Boldova Pasamar. Catedrático de Derecho Penal de la Universidad de Zaragoza y Doctor en Derecho por la misma Universidad. Correo electrónico: mboldova@unizar.es

${ }^{3}$ Carlos Fuertes Iglesias. Abogado del Real e Ilustre Colegio de Abogados de Zaragoza. Máster Universitario en Investigación y Especialización en Derecho por la Universidad de Zaragoza y Doctorando en Derecho por la misma Universidad. Correo electrónico: cfuertes@unizar.es 


\section{Introducción}

El interés reciente por la pornografía de menores hemos de situarlo cronológicamente en los años sesenta en los Países Bajos, donde eclosiona como fenómeno de manera simultánea a la llamada "revolución sexual" en los Estados Unidos (Boldova, 2008; 2010). Esta situación coadyuvó al incremento de la producción y difusión de pornografía de personas menores de edad. Así, para 1977 se hallaban en circulación en Estados Unidos alrededor de 250 revistas de pornografía infantil (Agustina, 2011). Fue esta eclosión de pornografía infantil la que impulsó su persecución legal a finales de los setenta y principios de los ochenta, causando finalmente que la producción y distribución de este tipo de pornografía disminuyera y quedará relegada en ámbitos marginales, con fotografías de baja calidad, difíciles de obtener y con un precio muy elevado (Agustina, 2011; Boldova, 2008).

No obstante, la revolución tecnológica que comenzó a partir de los años noventa, con la popularización de internet, generó un resurgimiento y un auge sin precedentes de la pornografía de personas menores de edad, lo que conllevó a una transformación sustancial de la problemática, ya que, debido al fácil y rápido acceso a toda clase de contenidos que ofrece internet, hace que la pornografía infantil se encuentre al alcance de cualquier persona; igualando sus cifras de ganancias a las de la industria de la pornografía de adultos (Agustina, 2011; Boldova, 2008; Rincón \& Naranjo, 2012). Este aspecto fue advertido de una manera paradigmática por el informe de Carnegie Foundation (1995), que apuntaba que 917.410 imágenes, descripciones, cuentos y animaciones pornográficas habían sido descargadas 8.5 millones de veces por clientes en más de 2.000 ciudades de cuarenta países, provincias y territorios. Asimismo, los estudios de Kuhn, Bloxsome \& Pope (2007) y Bureau of Justice (2007) evidencian que el fenómeno se ha perpetuado hasta la actualidad, donde la tendencia apunta a un incremento paulatino.

A la revolución tecnológica generada por el surgimiento de internet se sumó la revolución de la tecnología móvil, la cual permitió que desde los teléfonos celulares se pudiese realizar la distribución de información entre personas con efectividad y rapidez. Esta ventaja también fue aprovechada por las personas que se dedican a la producción y distribución de pornografía infantil (Agustina, 2011). Así, en la actualidad nos encontramos en un momento de franca expansión del fenómeno delictivo con los medios telemáticos como factor comisivo determinante.

\section{Definición de pornografía infantil}

A pesar de que la pornografía infantil no es aceptada socialmente, a la hora de definir el término no existe una opinión unánime (Miró, 2012; Morilla Fernández, 2005), debido a que la construcción de un concepto único depende de varios factores tales como la cultura, la moral, la religión, así como las pautas concretas de comportamiento sexual de cada sociedad (Sanz, 2009). No obstante, Boldova (2008) afirma que en principio y en sentido estricto hay que entender a la pornografía infantil como aquel material que incorpore a una persona menor de edad real en una conducta sexual explícita. Esta definición, sin entrar en matizaciones, puede entenderse como de común aceptación o que no admite cuestionamientos. Similar definición aporta Morillas (2005).

De igual forma, Boldova (2010) aconseja utilizar la denominación de pornografía de menores, que no es necesariamente pornografía infantil, por cuanto esta es una modalidad de la primera, que engloba precisamente no solo a los infantes, sino también a adolescentes (prepúberes y púberes) y jóvenes menores de edad. Por lo tanto, el calificativo "de menores" nos resulta mucho más satisfactorio terminológicamente, tanto desde la óptica exclusivamente penalista como criminológica del fenómeno.

Entre las características de la pornografía de menores de edad tenemos, en primer lugar, que esta consiste en una representación visual que puede realizarse en todos aquellos documentos susceptibles de ser representados (Morillas, 2005), teniendo dicha representación como característica fundamental mostrar al niño o la niña completo, reproduciendo lo más realmente posible su rostro (Rincón \& Naranjo, 2012) y sus partes genitales con fines predominantemente sexuales, es decir, que dichas representaciones sean las de actividades sexuales explícitas (De Luca \& López, 2009). En segundo lugar, las imágenes proyectadas o divulgadas deben ser reales, por lo tanto, no serán consideradas como pornografía infantil aquellas que muestren a personas menores de edad irreales creadas a través de computadora u otras técnicas (Morillas, 2005); o cuando se trate de adultos que simulen ser menores de edad (Boldova, 2008). 


\section{Las tecnologías de la información y la comunicación como medios de comisión de la pornografía de personas menores de edad}

En los últimos años, la sociedad en general ha experimentado una revolución en el desarrollo de la ciencia y las tecnologías de la información y la comunicación (TIC), lo cual ha facilitado el desarrollo de diversas actividades en pro del bienestar social. Lamentablemente, estas tecnologías también han sido utilizadas para la ejecución de delitos, y, en concreto, se ha utilizado a la informática como medio para la consumación de delitos, o como objeto de efectivización de una conducta disvaliosa (Rincón \& Naranjo, 2012), a tal punto que se ha llegado a afirmar que el número de delitos virtuales es muy superior al de delitos reales (Urbano, 2009).

En esta línea, los delitos relacionados con la pornografía de personas menores de edad, a pesar de no ser un fenómeno propiamente informático, están cada vez más vinculado al uso de las TIC, llegándose a afirmar que en la actualidad la mayoría de los comportamientos vinculados con la pornografía de menores se realizan principalmente a través de internet (De Luca \& López, 2009; Rosa, 2011). Esta utilización de internet como medio comisivo de delitos relacionados con pornografía de personas menores de edad ha pasado por varias fases. En este sentido, en un primer momento, durante la década de los noventa, se empleaban páginas web alojadas en servidores de internet en las que se ponía material pornográfico infantil a disposición de los usuarios a través de pagos por medio de tarjeta de crédito. Así, en esa época la creación de una página de contenido pornográfico infantil podía realizarse fácilmente, resultando sencillo encubrir la oferta de este tipo de pornografía con informaciones falsas sobre adopciones, ofertas de empleo, etc. (Morillas, 2005; Rojo, 2002).

A medida que se intensificó la persecución de personas que compraban y vendían pornografía de personas menores de edad a través de páginas web, se fue abandonando esta modalidad para comenzar a utilizar los chats desarrollados en tiempo real, los grupos de noticias y foros. Estas modalidades permiten a los pedófilos ponerse de acuerdo para intercambiarse pornografía de menores de edad, ya sea a través de envíos al correo electrónico, por la compra directa en una página web o por la descarga de archivos, contando con la ventaja de la privacidad que estos medios ofrecen a los usuarios, dificultando que se les detecte y persigua por este tipo de conductas (Rojo, 2002; Morales F., 2002).

En un tercer momento, ante las investigaciones realizadas por agentes encubiertos en las salas de chat, los consumidores comienzan a asociarse sin ánimo de lucro y se comparten fotografías de pornografía de personas menores de edad a través de técnicas de intercambio de fórmulas como send to receive, o con personas que se encuentren conectadas a la red, utilizando un mismo programa. Así, los usuarios de los programas de archivos compartidos ponen en común su material pornográfico con otros usuarios sin necesidad de entablar contacto directo (Wortley \& Smallbone, 2012).

En este sentido, se hace referencia a dos tipos de protocolo: el Protocolo Peer-to-Peer (P2P) y el Protocolo de Transferencia de Ficheros (FTP). El P2P (de igual a igual), permite que los servidores posean una descripción de los archivos de las computadoras conectadas a él, facilitando de esta manera la distribución de pornografía de personas menores de edad. Mientras que el FTP es más antiguo $\mathrm{y}$, por lo tanto, menos usado para la propagación de este tipo de pornografía, ya que no cuenta con buscadores que permitan saber qué computadoras actúan como servidores FTP, aunque sí que existen páginas web que proporcionan listas de servidores con una descripción general de los archivos almacenados.

\section{La prueba técnico-científica}

En los delitos vinculados con la pornografía de menores, cobra gran importancia la aplicación de métodos científicos y procesos de laboratorio para establecer la realidad de la conducta delictiva en su integridad $y$, consecuentemente, hacer justicia. Y es que en este "nuevo mundo" de las TIC, dada las especificidades que plantea, exige un uso de la técnica y la ciencia en armonía con la regulación penal y procesal penal, a fin de reconstruir la conducta vinculada con pornografía de personas menores de edad que conllevará a una correcta adecuación típica (Morales G., 2010; Urbano, 2009).

Así, durante los procesos de investigación, las autoridades competentes obtienen datos informáticos tales como archivos de registro que muestran qué usuario estaba conectado a la computadora, el tiempo de duración de la sesión, registros de cuándo un equipo se conecta a 
internet, las entradas del historial del navegador, los registros de correo electrónico y chat, entre otros; tales datos podrían convertirse en pruebas delictivas, $y$, por lo tanto, necesitan ser recuperados y autenticados para poder utilizarlos posteriormente en los procesos penales, lo cual se dificulta debido a la volatilidad y facilidad de manipulación, falsificación, protección tecnológica o eliminación de los datos electrónicos (Comisión de las Comunidades Europeas, 2001; Wortley \& Smallbone, 2006).

Por esta razón, este tipo de pruebas deben ser realizadas por forenses informáticos, quienes desarrollan y utilizan protocolos y procedimientos científicos para investigar los datos informáticos y para analizar y mantener la autenticidad de los datos recuperados, y, consecuentemente, mantener la garantía de la objetividad de la prueba al momento de ser valorada dentro del proceso penal (Comisión de las Comunidades Europeas, 2001; Urbano, 2009). Así, se vuelve indispensable la práctica de peritajes informáticos cuando nos encontremos ante delitos cometidos por medio de las $\mathrm{TIC}$, teniendo en cuenta la necesidad de que los resultados y conclusiones de dichos peritajes se presenten en un lenguaje expositivo de máxima claridad para asegurar la objetividad y transparencia en su valoración. Asimismo, la pericia informática contribuye en el control de la licitud de la actuación de los investigadores, pues garantiza la imparcialidad de los resultados de las diligencias de investigación (Ribas, 2006; Urbano, 2009).

En esta línea, dado que la valoración de la prueba técnicocientífica tiene que guardar un estricto respeto a las reglas y principios científicos, y así alejarla de valoraciones arbitrarias, es necesario que los jueces conozcan estos principios fundamentales de las ciencias y técnicas relacionadas con las TIC, a fin de realizar una auténtica y correcta valoración de los medios de pruebas obtenidos a través de métodos técnicos científicos para reconstruir la conducta delictiva (Morales G., 2010; Urbano, 2009). Por lo tanto, el juez debe llevar a cabo una valoración racional, atribuyéndole a la prueba científica un determinado peso en la formación de su convicción sobre el hecho principal; y para ello ha de tener en cuenta: el valor estadístico de la prueba; la existencia de otras pruebas o indicios; $y$, sobre todo, la relación de la prueba con el hecho principal que se pretende probar (Sociedad Farmaquímicos Salvadoreños vs. Alfaro, 2010).
Análisis de sentencias dictadas por tribunales salvadoreños relacionadas con el uso de las tecnologías de la información y la comunicación en delitos de pornografía de menores de edad

\section{Sentencia 453-cas-2010 de la Sala de lo Penal de la Corte Suprema de Justicia}

Esta sentencia, de fecha diecinueve de octubre de dos mil doce, se pronuncia sobre la solicitud de casación realizada por dos imputados mayores de edad condenados por el Tribunal de Sentencia de Santa Tecla por el delito de posesión de pornografía sancionado en el artículo 173-A del Código Penal. Los principales argumentos se basan en la ilicitud de la obtención de la clave de la computadora que contenía material pornográfico infantil, y en la violación de la cadena de custodia de dicha computadora. Respecto al primer supuesto, la defensa alegó que el allanamiento realizado en la casa de habitación de los imputados fue ejecutado de forma violenta por los agentes policiales, quienes intimidaron al imputado de forma violenta y sicológica, a fin de obtener la clave para acceder a la computadora de este, violentando con este proceder las reglas procesales para el registro previo que amparaba la orden emitida, así como otras garantías y derechos del imputado, tales como los de audiencia, contradicción procesal, a la asistencia técnica de un abogado y el derecho a no declarar contra sí mismo o declararse culpable.

Al respecto, la Sala manifestó que al analizar la prueba testimonial y documental presentada en juicio se establece que
"el imputado cuando porparte de uno de los agentes de policía fue preguntado de forma general si se conocía la clave de la computadora (...) el joven contestó 'que si la conocía pues la computadora era de su padre y él le daba mantenimiento', lo que implica, que el procesado no fue conminado a dar dicha información [...] pues de haber sucedió [sic] así, el defensor debió procurar que se hiciera constar en acta, ello con el objeto de ser discutido en juicio".

Esta situación fue acreditada por los testigos de cargo, por lo tanto, la Sala manifestó tener la convicción de que no se 
había conminado al imputado en una forma violenta a que proporcionara la clave de la computadora, sino que había sido proporcionada voluntariamente.

En nuestra opinión, la investigación de delitos y la obtención de pruebas deben realizarse de manera rápida y eficaz, para que no se pierdan pruebas importantes en los procedimientos de aplicación de la ley, siendo indispensable que estos procedimientos se realicen salvaguardando los derechos humanos y constitucionales, incluida la protección de la intimidad y de los datos.

No obstante, en el caso en estudio, a pesar de que la defensa alegó que la clave había sido obtenida de forma violenta, no pudo acreditar este hecho durante el juicio, por lo cual nos parece correcta la decisión de la Sala de no dar por sentada la violación del derecho al imputado a no declarar contra sí mismo. En este sentido, apuntamos la importancia de que tanto los sujetos procesales como los investigadores policiales tengan siempre presente la necesidad de hacer constar, en los distintos actos de investigación y procesales, aquellas situaciones que consideren vulneran los derechos de las partes, o que atenten contra los principios y garantías procesales, a fin de evitar la impunidad de situaciones lesivas de derechos.

En cuanto a la manipulación de evidencia, la defensa argumentó que en la experticia realizada a la computadora secuestrada durante el allanamiento de la casa de habitación de los imputados, la prueba había sido manipulada pues, como constaba en las actas del laboratorio de la PNC,

se hizo necesario extraer el disco duro porque la computadora no funcionaba bien y se utilizó como disco esclavo, es decir, se manipulo [sic] el disco duro y evidencia que contenía sin ningún control de la Fiscalía ni la defensa, aunado a eso se expresa en el informe que hubo un incendio en el laboratorio por lo que la computadora presenta colores distintos y se adicionó en otra máquina (...) con lo expresado por el testigo-perito se confirma que hubo manipulación de la evidencia sin control de ninguno de las partes, por lo que se pone en duda la veracidad de la prueba.

Al respecto, el tribunal ad quo manifestó en su sentencia que no consideraba que se hubiese roto la cadena de custodia, puesto que en el acta de registro podía advertirse que el recolector había permanecido de forma constante en el lugar y que este había entregado la evidencia al perito del laboratorio de la Policía Nacional Civil (PNC). Por lo tanto, consideró que materialmente existió cadena de custodia, ya que hubo una sola persona encargada del análisis y que en todo momento manifestó que tuvo control sobre ella hasta el momento que entregó los resultados.

Al respecto, apuntamos que dentro de los procedimientos técnicos científicos que debe realizar el perito a cargo del análisis de una computadora están el realizar una copia exacta del contenido del disco duro, o de otros dispositivos informáticos confiscados, tales como memorias USB, discos duros portátiles, $C D$, etc., garantizando que la copia "espejo" coincide con la original, debiendo conservarse bajo dominio judicial, por si fueran necesarias posteriores contrapericias (Velasco, como se citó en Rosa, 2011). Por lo tanto, la acción realizada por el perito, en el caso en estudio, parece estar adecuada a la diligencia exigida en este tipo de casos, en cuanto a garantizar que la información contenida en el disco duro se mantenga íntegra. Asimismo, dada la calidad habilitante de los peritos permanentes adscritos a la División Técnica y Científica de la PNC, se otorga a los peritajes realizados por estos el carácter de objetividad, imparcialidad e idoneidad (El Salvador vs. Durán, 2008).

En cuanto a la argumentación de la defensa de que las partes técnicas debieron estar presentes al momento de efectuar el peritaje, la Sala manifestó que ya existe un criterio asentado respecto a la calidad habilitante de los peritos permanentes adscritos a la División Técnica y Científica de la PNC, puesto que esta investidura oficial les otorga el carácter de objetividad, imparcialidad e idoneidad, al contar la institución policial con el personal experto permanente dedicado a explotar su conocimiento. Por consiguiente, y en razón de esta habilitación especial, no se vuelve necesaria para validar el dictamen pericial la presencia del juez y las partes. Por tanto, la Sala manifestó que no se concurrió en la ilegalidad observada por los peticionarios.

En nuestra opinión, coincidimos con que la policía se encuentra también facultada para examinar o acceder al contenido de las computadoras, respetando los principios de necesidad y proporcionalidad (Velasco, como se citó en de la Rosa, 2011; Pichardo vs. Sala de lo Penal del Tribunal Supremo, 2002). Por consiguiente, también nos parece acertada la opinión de la Sala de lo Penal salvadoreña 
cuando afirmó que en razón de esta especial habilitación no se vuelve necesario, para validar el dictamen pericial, la presencia del juez o las partes cuando se realicen estos peritajes, pero si es deseo de estos comparecer a tales diligencias, están facultados para hacerlo, siempre que se haga una solicitud pertinente al juez del proceso.

\section{Sentencia de la Cámara Tercera de lo Penal de la Primera Sección del Centro, de veinte de diciembre de dos mil doce}

Esta sentencia se pronuncia sobre el recurso de apelación interpuesto por la Fiscalía General de la República contra la resolución que decretó el sobreseimiento provisional del imputado por los delitos de remuneración por actos sexuales o eróticos y posesión de pornografía, regulados y sancionados en los artículos 169-A y 173-A del Código Penal.

En lo concerniente al delito de posesión de pornografía, consta que entre las diligencias realizadas se efectuó el registro con prevención de allanamiento en la casa de habitación del imputado, encontrándose "fotografías de personas del sexo femenino con poca ropa, sin ropa $y$ en posiciones de contenido sexual". A fin de comprobar si las personas que aparecían en dichas fotografías eran menores de 18 años, se procedió a solicitar un peritaje del Instituto de Medicina Legal para que un médico forense determinara las edades de dichas personas. Al respecto, el jefe del Departamento de Clínicas Forenses informó mediante oficio que "no es posible determinar la edades de las personas que aparecen en las fotografías que obran como secuestro en la presente causa penal", puesto que se requiere de un examen físico y odontológico, por lo que no pudo establecerse la minoría de edad de las personas que aparecen en las fotografías.

En este sentido, la Cámara valoró, en primer lugar, que si bien se ha comprobado el elemento objetivo del posesión y propiedad de la fotografías, no se ha logrado establecer la edad de las personas que aparecen en dichas fotografías. Por lo tanto, consideró que no se puede establecer la existencia del tipo penal y confirmó el sobreseimiento provisional decretado por la jueza del Juzgado Noveno de Instrucción.

En relación con el examen y valoración de fotografías con contenido pornográfico, a fin de determinar la edad de las personas que aparecen en estas, se ha establecido que en los casos en que, con el simple visionado de las fotografías, cualquier adulto medio advierte por el aspecto que se trata de niños o niñas, procede aplicar el principio notoria non egent probationem: los hechos notorios no necesitan prueba. Así, si al examinar videos o fotografías se evidencia, por los rasgos externos de las personas que aparecen en estos que las imágenes son claramente infantiles, se podía concluir, sin margen de duda, que en la elaboración de ese material pornográfico fueron utilizadas personas menores de edad (España vs. Anónimo, 2009; 2008).

Sin embargo, cuando las personas que aparecen en las fotografías o videos están en las últimas fases de desarrollo sexual, tanto la doctrina (Rosa, 2011) como la jurisprudencia (España vs. Anónimo, 2006) han manifestado que, de no poder establecerse con absoluta certeza que en efecto las personas que aparecen en el material pornográfico son menores de 18 años, habrá necesariamente que valorar la prueba en beneficio del reo, procediendo en estos casos la absolución del imputado, por la aplicación del principio indubio pro reo. Por lo tanto, únicamente se podrá tener dicha certeza si resulta posible individualizar a las víctimas que aparecen en el material pornográfico.

En este sentido, nos parece acertada la resolución adoptada por la Cámara Tercera de lo Penal cuando confirmó el sobreseimiento provisional por no haberse podido establecer que las personas que aparecen en las fotografías que poseía el imputado eran menores de 18 años. En esta línea, Rosa (2011) recomienda echar mano de otras fuentes para individualizar a las víctimas que aparecen en el material pornográfico. Así, se podrían analizar las pertenencias del imputado, a fin de verificar si este ha registrado los nombres, direcciones, fechas 0 cualquier otro tipo de información relacionada con las fotografías encontradas. También aconseja tener en cuenta la utilización de bases de datos de personas menores de edad víctimas de pornografía infantil, tales como el Child Victim Identification Program (CVIP), el Child Recognition and Identification System (CRIS) que son administradas por el National Center for Missing \& Exploited Children's (NCMEC); o las bases de datos que posee la Interpol, y que en el pasado ya han servido para identificar y rescatar a víctimas de pornografía.

En conclusión, en el resto de supuestos en los que no sea posible dicha individualización o identificación de la 
persona afectada y su consiguiente edad en el momento de la realización del material pornográfico, la determinación de que nos encontramos ante menores de edad deberá basarse en una apreciación subjetiva del juzgador que considere que dicha probabilidad de edad es rayana en la certidumbre.

\section{Sentencia 451-cas-2004 de la Sala de la lo Penal, de diecinueve de julio de dos mil cinco}

Esta sentencia se pronuncia sobre el recurso de casación interpuesto por las representantes de las víctimas - dos personas menores de edad de sexo femenino-, por haberse absuelto al imputado de los delitos de violación y agresión sexual agravada, corrupción de menores e incapaces y utilización de menores con fines pornográficos y exhibicionistas, previstos en los Arts. 160, $162 \mathrm{~N}^{\circ} 3,167 \mathrm{y}$ 179 del Código Penal en el año 2004.

En cuanto al delito de utilización de menores con fines pornográficos y exhibicionistas, el Tribunal Cuarto de Sentencia de San Salvador resolvió absolver al imputado utilizando las reglas de la exclusión probatoria, por entender que los videos conteniendo material pornográfico presentados como prueba en el juicio fueron obtenidos de manera ilícita, pues el procedimiento realizado por la PNC fue irregular.

El tribunal ad quo consideró acreditado que nunca hubo un real y apropiado despliegue de actividad investigativa por parte de la PNC, tal como lo exige el Principio de Mínima Actividad Probatoria, ya que una llamada telefónica anónima - cuya existencia el tribunal ad quo dejó entredicha- originó el registro de la vivienda del imputado, "no existiendo, por parte de la policía un real y apropiado despliegue de actividad investigativa, tendiente a la verificación efectiva del hecho anoticiado". Asimismo, el tribunal ad quo manifestó que

no resulta suficiente argumento para solicitar y/o autorizar la violación a derecho o garantía fundamental -en este caso la morada $y$ subsecuente intimidad personal y/o familiar-, la existencia únicamente de la llamada telefónica anónima que pudo haberse efectuado a delegación policial... pues se lesionaría gravemente el Principio de Proporcionalidad.
Por su parte, el tribunal ad quem manifestó que será prueba irregular o defectuosa toda aquella prueba en cuya obtención se haya infringido la legalidad ordinaria y/o se ha practicado sin las formalidades legalmente establecidas para la obtención y práctica de la prueba; y si lo que se infringe es un derecho o garantía fundamental estaríamos ante una prueba prohibida. En este sentido, el tribunal ad quem consideró que la llamada telefónica originó "de manera casi automática" el registro de la vivienda del imputado, limitándose la Policía a realizar dos actuaciones necesarias pero insuficientes para justificar una solicitud de orden judicial para ingresar al domicilio, por lo tanto, no existió por parte de la Policía un real y apropiado despliegue de actividad investigativa, tendiente a la verificación efectiva del hecho noticiado. Así, era preciso que la Policía llevara a cabo las diligencias de investigación necesarias para confirmar o desestimar la sospecha inicial producto del aviso anónimo. Por lo tanto, el tribunal consideró que "conforme a la evidencia presentada en juicio, no hubo despliegue policial justificatorio del registro; razón por la que este argumento carece de asidero para casar la sentencia".

Al respecto de la postura adoptada, tanto por el Tribunal ad quo como el ad quem, es válido citar la jurisprudencia salvadoreña adoptada en situaciones similares. Así, la Sala de lo Penal de la Corte Suprema de Justicia (El Salvador vs. Portillo, 2003) ha establecido que el acto de registro y allanamiento constituye una diligencia inicial de investigación, que por supuesto requiere de una orden judicial por ser de aquellas actividades que lesionan derechos fundamentales, los cuales ceden ante determinados valores que en casos individualizados hacen necesaria la injerencia en el ámbito privado domiciliario, tales como la investigación de hechos delictivos bajo la tutela y garantía del Órgano Judicial.

Asimismo la Sala de lo Penal (Ruiz vs. Ayala, 2006) ha establecido que la PNC puede, por iniciativa propia, solicitar una orden de registro siempre y cuando su actuación, dentro del proceso penal, se ejecute bajo el control y dirección de la Fiscalía General de la República, la cual, al ejecutar este control, se convierte en garante de la constitucionalidad y legalidad de las actuaciones de la Policía. De igual forma, el ente jurisdiccional, al dictar una resolución motivada, en la que explica las razones de la limitación y que se sustenta en actos o elementos concretos de investigación, cimenta la limitación de 
derechos fundamentales que autoriza, siendo a la vez una manifestación concreta de las garantías protegidas dentro de un Estado constitucional y democrático. Por lo tanto, el juez debe valorar la información o los elementos de juicio en que se basa la imputación, debiendo reflejar que la información es suficiente para justificar esa grave intromisión a la intimidad. Por consiguiente, la autorización jurisdiccional de allanamiento y registro de un lugar debe pronunciarse en el marco de una investigación y la decisión debe estar adecuadamente motivada, es decir, que explique las razones por la que debe aceptarse la limitación de este derecho (El Salvador vs. Portillo, 2003).

En similar sentido, la Sala de lo Penal (El Salvador vs. Aguilar, 2004; El Salvador vs. Castellanos, 2003) estableció que el allanamiento y registro han de ser excepcionales y proporcionales a la finalidad que se persigue, y exige que la injerencia en la morada facilite la obtención del éxito pretendido; además, tiene que darse la necesidad o excepcionalidad, concediéndose la entrada cuando no hay otros caminos menos gravosos para llegar al descubrimiento del hecho delictivo. Por lo tanto, se hace necesario que esta proporcionalidad se ampare en una adecuada investigación preliminar que justifique la vulneración del derecho a la intimidad de morada del procesado.

En esta línea, en la sentencia Salvador vs. Aguilar (2001), el Tribunal de Sentencia de Sonsonate cuestionó la ejecución de una Orden de Registro y Allanamiento girada por autoridad judicial puesto que la supuesta investigación preliminar realizada por la Policía no constó materialmente agregada al expediente. Así, el Tribunal manifestó que "el procedimiento policial carece de elementos suficientes cuando (...) se basaron en una supuesta investigación preliminar, que dio lugar a una orden de registro $y$ allanamiento girado por orden judicial (...)".

Por lo tanto, consideramos relevante recalcar la importancia que tiene la ejecución de los actos de investigación y de recolección de pruebas. Tal como sucedió en la sentencia en estudio, a pesar de tener pruebas que podrían haber incriminado al imputado por el delito de utilización de personas menores de 18 años, deficientes mentales e incapaces en pornografía, no se pudo valorar dicha prueba ni analizar si la conducta del sujeto activo se ajustaba al correspondiente tipo penal.
En este sentido, es necesario que los investigadores y agentes de policía conozcan bien los procedimientos que se deben seguir en estos actos de investigación, a fin de garantizar la persecución de estos delitos y la protección de los derechos de las víctimas. Concretamente, del estudio de esta sentencia podemos concluir que es necesario que la Policía fundamente y haga constar de manera adecuada y suficiente sus diligencias de investigación para justificar, conforme a derecho, su actuar policial. Todo esto para evitar este tipo de impugnaciones que conllevan a la vulneración de los derechos de las víctimas y a la impunidad de los explotadores sexuales.

\section{Referencias}

El Salvador vs. Aguilar, P0601-5-2001 (Tribunal de Sentencia de Sonsonate 07 de marzo de 2001).

Pichardo vs. Sala de lo Penal del Tribunal Supremo, STC 070/2002 (Sala Primera del Tribunal Constitucional 3 de abril de 2002).

El Salvador vs. Castellanos, C262-02 (Sala de lo Penal de la Corte Suprema de Justicia 02 de septiembre de 2003).

El Salvador vs. Portillo, C 194-02 (Sala de lo Penal de la Corte Suprema de Justicia 28 de octubre de 2003).

El Salvador vs. Aguilar, 132-CAS-03 (Sala de lo Penal de la Corte Suprema de Justicia 09 de marzo de 2004).

España vs. Anónimo, 58/2006 (Audiencia Provincial de Alicante, Sección Primera 30 de enero de 2006).

Ruiz vs. Ayala, 331-CAS-2005 (Sala de lo Penal de la Corte Suprema de Justicia 04 de enero de 2006).

El Salvador vs. Durán, 232-CAS-2007 (Sala de lo Penal de la Corte Suprema de Justicia 16 de enero de 2008).

España vs. Anónimo, 292/2008 (Tribunal Supremo, Sala Segunda de lo Penal 28 de mayo de 2008).

España vs. Anónimo, 188/2009 (Audiencia Provincial de Barcelona, sección segunda 16 de marzo de 2009).

Sociedad Farmaquímicos Salvadoreños vs. Alfaro, 682-CAS2007 (Sala de lo Penal de la Corte Suprema de Justicia 25 de enero de 2010).

Agustina, J.R. (2011). "¿Debe perseguirse penalmente la pornografía producida por y entre menores?". En T. S. Institute, La pornografía. Sus efectos sociales y criminógenos. Una aproximación multidisciplinar. (pp. 85-149). Montevideo-Buenos Aires: Bdef.

Boldova, M.Á. (2008). Pornografía infantil en la red. Fundamento y límites de la intervención del derecho penal. México D.F.: Ubijus. 
Boldova, M.Á. (2010). “Pornografía infantil en la red. Fundamento y límites de la intervención penal". En Romeo , \& Sánchez, La adaptacion del Derecho Penal al desarrollo social y tecnológico. Granada: Comares.

Bureau of Justice. (Diciembre de 2007). Prosecution of Child Sex Exploitation Offenders. Bureau of Justice Statistics Bulletin.

Carnegie Foundation. (1995). Marketing Pornography on the Information Superhighway. Georgetown Law Journal.

Comisión de las Comunidades Europeas. (26 de enero de 2001). Comunicación de la Comisión al Consejo, al Parlamento Europeo, al Comité Económico y Social y al Comité de las Regiones. Creación de una sociedad de la información más segura mediante la mejora de la seguridad de las infraestructuras de información y la lucha contra los delitos informáticos ([COM(2000) 890 final]). Bruselas.

De Luca, J.A., \& López, J. (2009). Delitos contra la integridad sexual. (J. L. Depalma, Ed.) Buenos Aires: Hammurabi.

Kuhn, K.-A., Bloxsome, E., \& Pope, N. (2007). The Pornography and Erotica industries: lack of research and need for a research agenda. International Nonprofit and Social Marketing Conference, Social entrepreneurship, social change and sustainability. Brisbane.

Miró, F. (2012). El Cibercrimen. Fenomenología y criminología de la delincuencia en el ciberespacio. Madrid: Marcial Ponds.

Morales, F. (noviembre de 2002). Fermín Morales - Pornografía infantil e Internet. Recuperado el 22 de octubre de 2013, de http://www.uoc.edu/in3/dt/20056/

Morales, G. (2010). ¿Sana crítica o apreciación técnico científica? Análisis de la disyuntiva en el sistema penal acusatorio. Bogotá: Grupo Editorial Ibañez.
Morillas, D.L. (2005). Análisis dogmático y criminológico de los delitos de pornografía infantil. Especial consideración de las modalidades comisivas relacionadas con Internet. Madrid: Dykinson S. L.

Ribas, J. (junio de 2006). La gran dificultad está en la interpretación de los informes periciales por parte del juzgador. Cybex e-newsletter (17), 3-7.

Rincón, J., \& Naranjo, V. (2012). Delito informático electrónico de las telecomunicaciones y de los derechos de autor. Bogotá: Ibañez.

Rojo, J. C. (2009). La realidad de la pornografía infantil en Internet. Revista de Derecho Penal y Criminología (9), 211-251.

Rosa, J.M. (2011). Los delitos de pornografía infantil. Aspectos penales, procesales y criminológicos. Valencia: Tirant lo blanch.

Rosa, J.M. (2012). "Delitos de pornografía infantil: Otra vuelta de tuerca". Diario La Ley (7817).

Sanz, N. (Enero de 2009). Pornografía en Internet. Revista Penal (23), 181-202.

Urbano, E. d. (2009). La valoración de la prueba electrónica. Valencia: Tirant lo Blanch.

Velasco, E. (s.f.). “Pericias informáticas: aspectos procesales penales". Revista de Jurisprudencia El Derecho (4).

Wortley, R., \& Smallbone, S. (2006). Applying Situational Principles to Sexual Offenses against Children. En W. Cullompton, Situational Prevention of Child Sexual Abuse: Crime Prevention Studies.

Wortley, R., \& Smallbone, S. (2012). Child Pornography on the Internet. Washington, DC: Community Oriented Policing Services. 